\title{
Shelf Life of Minimally Processed Honeydew, Kiwifruit, Papaya, Pineapple and Cantaloupe
}

\author{
R.E. O'CONNOR-SHAW, R. ROBERTS, A.L. FORD, and S.M. NOTTINGHAM
}

\begin{abstract}
This study was to determine the shelf life of minimally processed honeydew melon, kiwifruit, papaya, pineapple, and cantaloupe stored at $4^{\circ} \mathrm{C}$. Sensory assessments were carried out at 3 -day intervals by highly trained panels until the end of shelf life. Microbiological counts were made immediately after dicing fruit and at the end of shelf life. Results indicated that both the length of shelf life and type of spoilage were related to fruit species. Minimally processed fruit had longer shelf life at $4^{\circ} \mathrm{C}$ than at temperatures recommended for whole fruit when these were greater than $4^{\circ} \mathrm{C}$. Spoilage of $4^{\circ} \mathrm{C}$-stored kiwifruit, papaya and pineapple pieces was not a consequence of microbial growth.
\end{abstract}

Key Words: melon, kiwifruit, papaya, pineapple, sensory, minimally processed

\section{INTRODUCTION}

MINIMAL PROCESSING has been defined as the handling, preparation, packaging and distribution of agricultural commodities in a fresh-like state, and may include processes such as dicing, trimming and low level irradiation (Shewfelt, 1987). Two positive attributes of a minimally processed commodity are convenience and fresh-like quality (Huxsoll and Bolin, 1989), and thus minimally processed fruit are becoming an important component of the food supply (Dougherty, 1990; Ronk et al., 1989). Biological processes such as respiration, ripening and senescence continue in fruit after harvest. The respiration rate indicates how quickly fruit may deteriorate (Labuza and Breene, 1989). Changes in flavor, texture and appearance occur during senescence (Charley, 1982; Powrie and Skura, 1991) and may be induced or enhanced by minimal processing (Shewfelt, 1986). Effects of slicing on sensory quality differ between climacteric and nonclimacteric fruit and with physiological age of climacteric fruit (Watada et al., 1990).

Minimal processing may increase microbial spoilage of fruit through transfer of skin microflora to fruit flesh where microorganisms can grow rapidly upon exposure to nutrient laden juices. The low $\mathrm{pH}$ of most fruit restricts the microflora to acid tolerant microorganisms such as fungi and lactic acid bacteria (LAB) (Brackett, 1987). Recommended tests for assessment of sanitation and manufacturing practices for fruit are enumeration of yeasts, molds and LAB (Subcommittee on Microbiological Criteria et al., 1985) and Enterobacteriaceae (International Commission on Microbiological Specification for Foods, 1978). Coliforms are part of the normal microflora of fruit and processing lines (O'Connor-Shaw et al., 1994).

With fruit which is not subject to chilling injury, low temperature storage is effective for prolonging shelf life. It inhibits respiration and transpiration of plant tissues and growth of microorganisms (Shewfelt, 1986). Tropical and subtropical produce suffer chilling injury when storage temperatures are $<12^{\circ} \mathrm{C}$ (Powrie and Skura, 1991; Rolle and Chism, 1987). Although the mechanisms of spoilage have been well studied, research integrating postharvest physiology and microbiology with shelf life

The authors are affiliated with IFIO, Queensland Department of Primary industries, 19 Hercules Street, Hamilton, Brisbane, OLD 4007, Australia. Address inquiries to Robyn Shaw. has not been reported (Shewfelt, 1986). Information has been reported on methods to control physiological and microbial spoilage of whole fruit (Bolin and Huxsoll, 1989; Kader, 1985; King and Bolin, 1989; Shewfelt, 1987). However, specific treatments of benefit to particular minimally processed fruits have not been reported.

We studied minimally processed (i.e. peeled, deseeded and diced) honeydew (melon), kiwifruit, papaya, pineapple, and cantaloupe. Our objectives were to compare shelf lives, identify sensory attributes, describe sequences of sensory changes leading to spoilage, and determine extent of their microbial spoilage. Optimum storage temperatures for whole honeydew, papaya and pineapple are $7-10^{\circ} \mathrm{C}, 13^{\circ} \mathrm{C}$, and $20^{\circ} \mathrm{C}$, respectively (Watkins and Ledger, 1990). Another objective was to determine whether those fruit, in minimally processed form, would undergo chilling injury when stored at $4^{\circ} \mathrm{C}$.

\section{MATERIALS \& METHODS}

\section{Fruit preparation}

Honeydew melons, kiwifruit (cultivar Hayward), papayas, pineapples (cultivar smooth cayenne) and cantaloupes were purchased at a local market. The fruit had no external defects. Fruit from different growers was used in three replicate trials.

For honeydew, papaya, pineapple and cantaloupe, four fruit were studied per trial, one fruit allocated per panelist. These fruit were cut into pieces approximating cubes, with sides 15 to $20 \mathrm{~mm}$ (avg weights 11, $9.1,5.2$ and $9.2 \mathrm{~g}$, respectively). Wedge shaped pieces (sides 15 to 20 $\mathrm{mm}$, avg weight $6.3 \mathrm{~g}$ ) from three or four kiwifruit were combined to provide samples for one panelist. A composite sample was not prepared for sensory analysis. We assumed that variability between fruit would exceed variability between panelists.

Fruit pieces were stored at $4^{\circ} \mathrm{C}$ and at respective recommended storage temperatures for whole fruits, when these were substantially $>4^{\circ} \mathrm{C}$. Additional storage at $8.5,13$ and $20^{\circ} \mathrm{C}$ was thus used for honeydew, papaya, and pineapple pieces, respectively (Watkins and Ledger, 1990). Diced fruit were stored in closed, circular ( $95 \mathrm{~mm}$ diam base, $125 \mathrm{~mm}$. diam top, $75 \mathrm{~mm}$ high), polypropylene containers (A.M.G.M., Port Klang Malaysia). Six containers of fruit were prepared for each storage temperature, for sensory analyses at six storage times. Minimal processing (i.e., peeling, deseeding and dicing) was done manually using good manufacturing practices, at ambient temperature $\left(\sim 20^{\circ} \mathrm{C}\right)$. Metal equipment was autoclaved; nonmetal equipment was sanitized by exposure to 200 $\mathrm{ppm}$ chlorine solution for $>15 \mathrm{~min}$. Bench tops were swabbed with alcohol. The fruit was not sanitized. Technicians did not wear gloves, masks, aprons or hats.

\section{Sensory evaluation}

Descriptive analysis was used to profile appearance, odor, flavor and texture attributes of fruit pieces (Stone et al., 1974). Quality scales for appearance, flavor and texture (based on fresh, ripe, high quality fruit obtained during training) were also included to monitor overall effects of attribute changes.

Selection and training of panelists. Twenty-three panelists were initially selected from IFIQ employees on the basis of availability and liking for the fruit under study. Triangle tests, according to Australian Standard AS 2542.2.2 (Standards Australia, 1983), were used to assess abilities to distinguish between fresh fruit and that which had been stored at elevated temperatures. Eleven panelists, who correctly identified the "different" fruit $>64 \%$ of the time, were selected for further training. 
Table 1-Attributes used to describe sensory characteristics of fruit Intensity

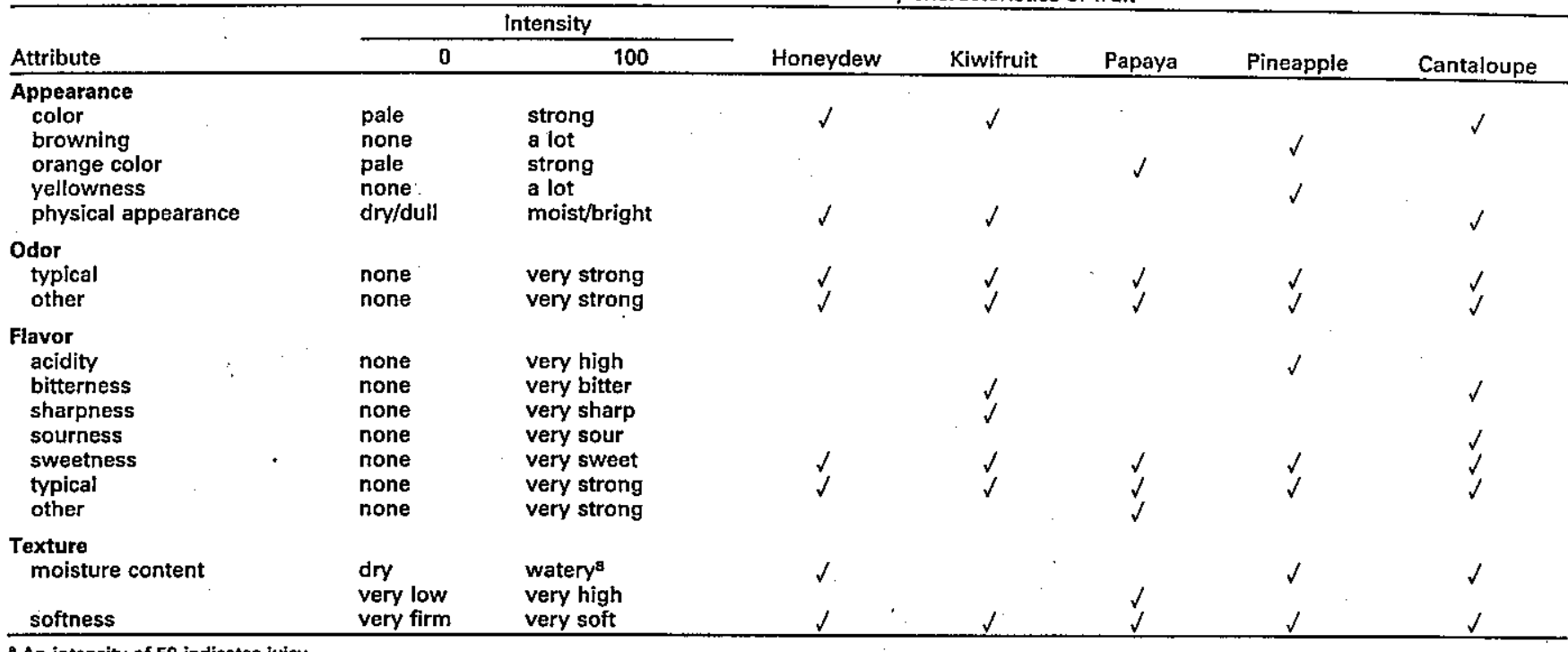
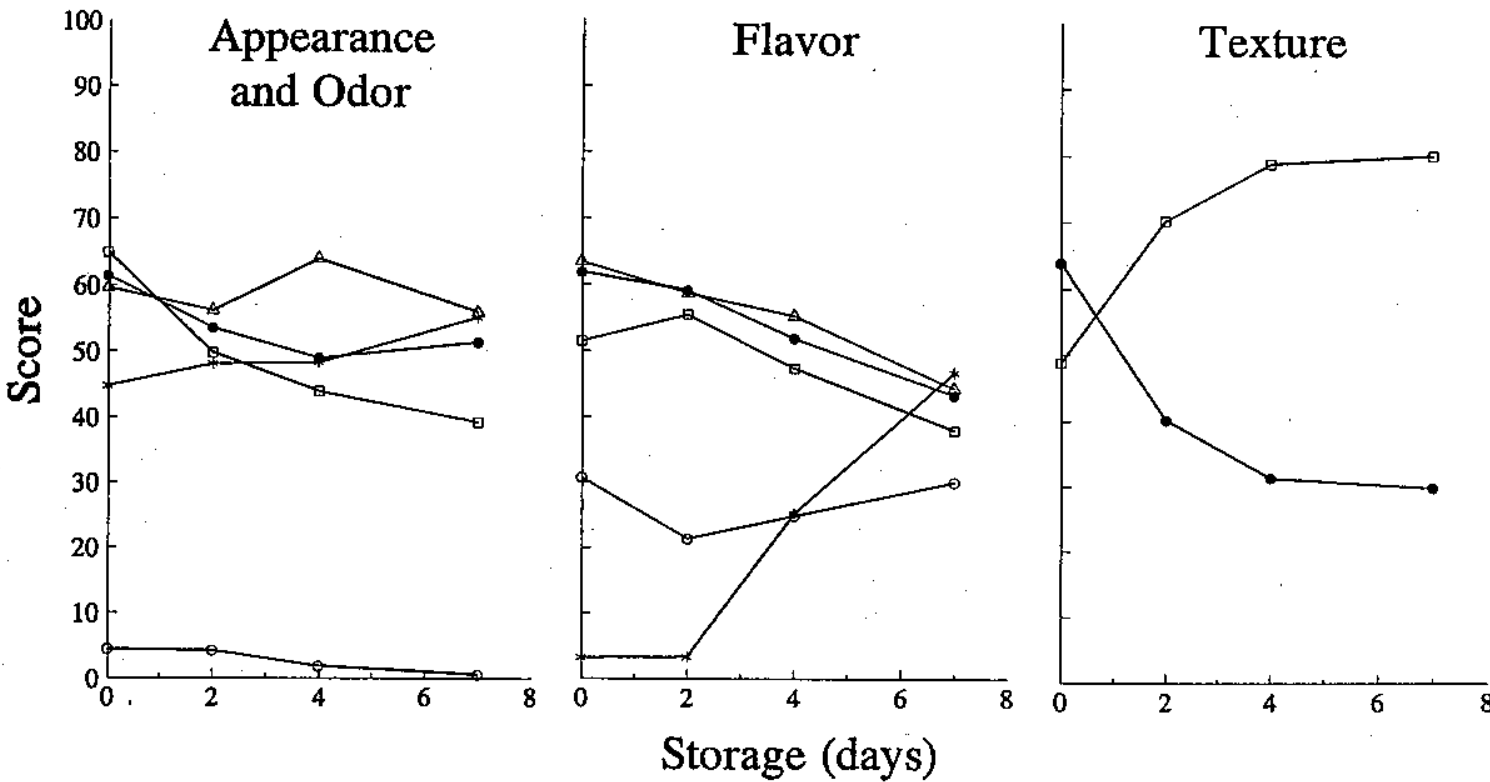

Fig. 1-Sensory changes in kiwifruit pieces during $4^{\circ} \mathrm{C}$ storage. Appearance: $\bullet$ quality $(5.11), \square$ physical appearance $(6.46),(*)$ color (5.08); Odor: $\Delta$ typical (4.66); 0 other (2.38); Flavor: $\bullet$ quality (4.37), $\Delta$ typical (5.33); $\square$ sweetness (5.32); $\circ$ sharpness (8.48), * bitterness (4.43); Texture: $\bullet$ quality (6.41), $\square$ softness (5.54). Standard errors of means in brackets. Intensity scales for each attriubte, Table 1. Quality scales rated from 0 extremely poor to 100 extremely good.

For each fruit species, lists of adjectives which described its appearance, odor, flavor and texture were developed (Table 1). Graphic line scales for each descriptor were marked by panelists. They could add other descriptive comments to scoresheets when tasting. The forms were pretested using fresh and aged fruit and modifications made when necessary. Panelists repeated assessments of standard fruit samples until confident with quality and attribute scales and agreed scores for each of the standard fruit samples. Training for each fruit lasted $\approx 4 \mathrm{wk}$.

The ability of panelists to discriminate and reproduce results was tested in replicate tests on fresh and aged fruit. A panel of four was selected for each fruit on the basis of their performance (as determined by analysis of variance), fruit preferences and distribution of workload. When a 2-mo delay or more occurred between successive trials, a refresher session was held. Panelists tasted fresh fruit to reacquaint themselves with both the scoresheets and typical quality attributes.

Storage trials. Sensory analyses were undertaken immediately after dicing (0 days), after $4,7,11,14$ and 18 days storage for honeydew, pineapple and cantaloupe, and after $2,4,7,9$ and 12 days storage for kiwifruit and papaya, until the fruit became inedible. If evaluators observed microbial colonies on fruit or a panelist considered fruit may be unfit for consumption, then only appearance and odor were scored. Four pieces of fruit were presented to each panelist at each session in a coded transparent bowl under white light (daylight equivalent). Fruit was served at ambient temperature $\left(\approx 22^{\circ} \mathrm{C}\right)$ to panelists in individual booths. When fruit was stored at different temperatures, both samples were presented at one session with order of presentation balanced across the panel.

Analysis of results. Numerical scores were attached to marks on the line scales using a digitizer pad (Houston Instruments HiPad Plus 9012, Houston, TX), and considering each scale to have left 0 and right 100 end points. Data for each attribute were analyzed according to a split plot factorial design. Because fruit came from different growers, and we assumed that this could influence sensory quality, growers were used as a blocking factor. Tasters were another factor and storage time the split plot factor. For honeydew, storage temperature was another factor. As both pineapple and papaya deteriorated quickly at higher storage tem- 

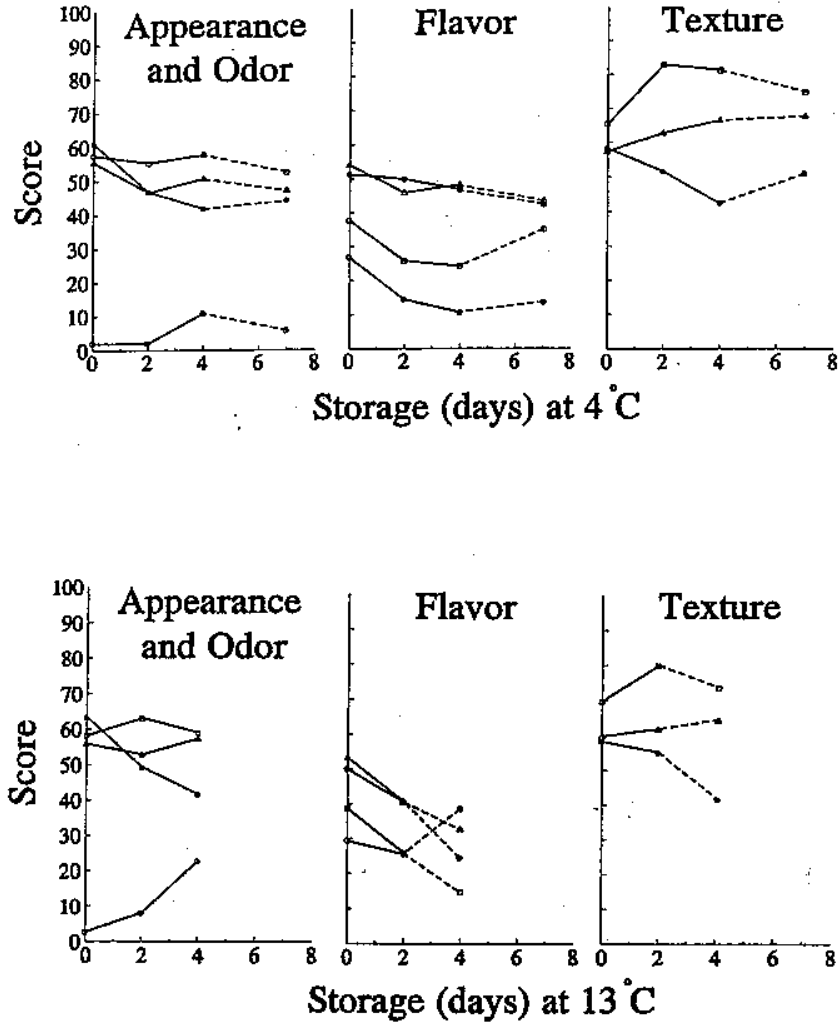

Fig. 2-Sensory changes in papaya pieces during $4^{\circ} \mathrm{C}$ and $13^{\circ} \mathrm{C}$ storage. Appearance: $\bullet$ quality $(4.63,5.08),\left(4^{\circ} \mathrm{C}, 13^{\circ} \mathrm{C}\right)$, $\square$ orange color (3.80, 3.34); Odor: $\Delta$ typical $(3.95,3.71)$, o other $(3.19,4.83)$; Flavor: • quality $(8.22,9.43), \Delta$ typical $(8.88,10.05)$, $\square$ sweetness $(7.66,7.91)$, 0 other $(7.08,10.06)$; Texture: $\bullet$ quality $(4.38,2.90)$, 口 softness $(5.79,4.42), \Delta$ moisture content, $(5.85,5.57)$. Standard errors of means in brackets. Intensity scales for each attribute, Table 1 . Quality scales rated from 0 extremely poor to 100 extremely good. For $4^{\circ} \mathrm{C}$ stored papaya, dashed lines indicate that at 7 days, fruit from two of the three replicates were assessed, unacceptable scores for the third set at $\mathbf{4}$ days terminated storage. For $13^{\circ} \mathrm{C}$ stored papaya, dashed lines indicate fruit from two replicates were assessed for flavor and texture as unacceptable appearance of the third set precluded further tasting.

peratures, insufficient data were collected to make valid comparisons between storage temperatures for them. Where a significant $(p<0.05) \mathrm{F}$ ratio for storage time was found, then pairwise treatment comparisons were made using least significant difference test $(p=0.05)$.

\section{Microbiological counts}

Microbiological counts were made immediately after dicing ( 0 days) and at the end of shelf life. For practical reasons, panelists' samples were combined for microbiological tests. The composite sample contained equal amounts of each panelist's allocation of fruit and consisted of 24 dice.

The fruit were diluted $1: 5$ in diluent containing $0.1 \%$ peptone and $0.5 \%$ sodium chloride and stomached for $1 \mathrm{~min}$. Subsequent 10 -fold dilutions were also made in this diluent. Total, Enterobacteriaceae, yeast, mold and lactobacilli counts were made by the pour plate method using $1 \mathrm{~mL}$ of inoculum. The medium and incubation conditions for each count were: total count, standard methods agar (Gibco Laboratories, Madison, WI), 3 days at $25^{\circ} \mathrm{C}$; Enterobacteriaceae count; violet red bile agar (Becton Dickinson Microbiology Systems, Cockeysville, MD) to which $1 \%$ dextrose was added, $5 \mathrm{~mL}$ overlay of the same agar, 1 day at $30^{\circ} \mathrm{C}$; yeast and mold count, dichloran rose bengal chloramphenicol agar made according to manufacturer's instructions (Oxoid, Basingstoke, Hants, UK), 5 days at $25^{\circ} \mathrm{C}$; and lactobacilli count, MRS agar (Becton Dickinson), anaerobic incubation for 6 days at $30^{\circ} \mathrm{C}$ in a $\mathrm{GasPak}^{\mathrm{R}}$ anaerobic jar with Gas Pak $^{\mathrm{R}}$ Plus anaerobic system envelopes (Becton Dickinson).
RESULTS

\section{Sensory evaluation}

In general, appearance, flavor and texture quality scores for fresh fruit ranged between 58 and 72. Exceptions were honeydew which received scores below 50 for appearance, flavor and texture. Low scores, near 50, were also given for papaya flavor, and cantaloupe flavor and texture. Fresh pineapple received the highest quality scores. We considered valid the inclusion of results for honeydew, papaya and cantaloupe despite their low. initial scores.

Honeydew melon. At $4^{\circ} \mathrm{C}$, changes in appearance, odor, flavor and texture attributes during storage were not statistically significant. Replicate three fruit were not tasted at 11 days because of translucent appearance. At $8.5^{\circ} \mathrm{C}$, no significant changes in appearance, odor, flavor and texture attributes were detected. Mold on replicate two fruit at 7 days precluded their tasting at that time.

Kiwifruit. At $4^{\circ} \mathrm{C}$ (Fig. 1), appearance scores did not change significantly with time. After 2 days, texture scores were lower than those for fresh fruit. This corresponded to an increase in softness. A bitter flavor developed by 4 days, and this was stronger after 7 days. The increased bitterness was probably the main contributing factor in the lower flavor of the 7 day stored fruit. Typical flavor intensity decreased steadily $(p=0.10)$ with time.

Papaya. At $4^{\circ} \mathrm{C}$ (Fig. 2), shelf life of papaya pieces was limited to 2 days due to a drop in appearance score. After 2 days, the pieces were softer than when fresh. Comments such as "broken down" appearance and "broken down" or "sloppy" texture were used on five, 2 day-stored papayas and probably describe changes in appearance and softness. These changes intensified on further storage. Replicate two papayas were not stored beyond 4 days because of unacceptable appearance, flavor and texture, which were given scores of 29,24 and 32 respectively, at 4 days. Unexpectedly, three panelists identified a bitter flavor in replicate one fruit at 0 days, but only one panelist detected bitterness at 2 days.

At $13^{\circ} \mathrm{C}$ (Fig. 2) within 2 days storage, papaya texture quality declined significantly. Four-day stored pieces rated lower for appearance than before storage, although no consistent changes in color intensity occurred. However, panelists commented on translucent appearance. The intensity of "other" odors, which could not be conclusively identified from comments, was higher in the 4 day stored papaya than initially. Colonies, (not identified), were found on fruit from replicates one and three at 4 days. The major differences in spoilage profiles of the 4 and $13^{\circ} \mathrm{C}$-stored fruit were that development of "other" odors and microbial colonies occurred more rapidly at higher temperature.

Pineapple. At $4^{\circ} \mathrm{C}$ (Fig. 3), all quality scores changed significantly over the duration of the trial, but no change in any sensory attribute was detected during the first 7 days storage. Scores for browning discoloration for 11-day stored fruit were higher than those for fresh fruit, and coincided with lower appearance scores. Those fruit were also softer than unstored fruit confirming a reduction in texture score. Fourteen-day stored pineapple had a lower "typical" odor intensity and a higher "other" odor intensity (described as fermented in three samples) than unstored fruit. By that time, pineapple from two trials were considered inedible because of unacceptable appearance (replicate one fruit had become excessively brown; mold was evident on replicate three fruit).

At $20^{\circ} \mathrm{C}$, statistical analysis of data was not carried out because of rapid deterioration. By 4 days, the fruit had become brown (scoring 3 and 74 at 0 and 4 days, respectively). Nine fruit had developed a fermented odor and mold was observed on replicate two and three fruit.

Cantaloupe. At $4^{\circ} \mathrm{C}$ (Fig. 4), a reduction in "typical" flavor of cantaloupe pieces occurred during the first 4 days. By 7 days, bitterness levels were lower and the fruit was firmer than initially. By 11 days, fruit were paler than they were initially, although 

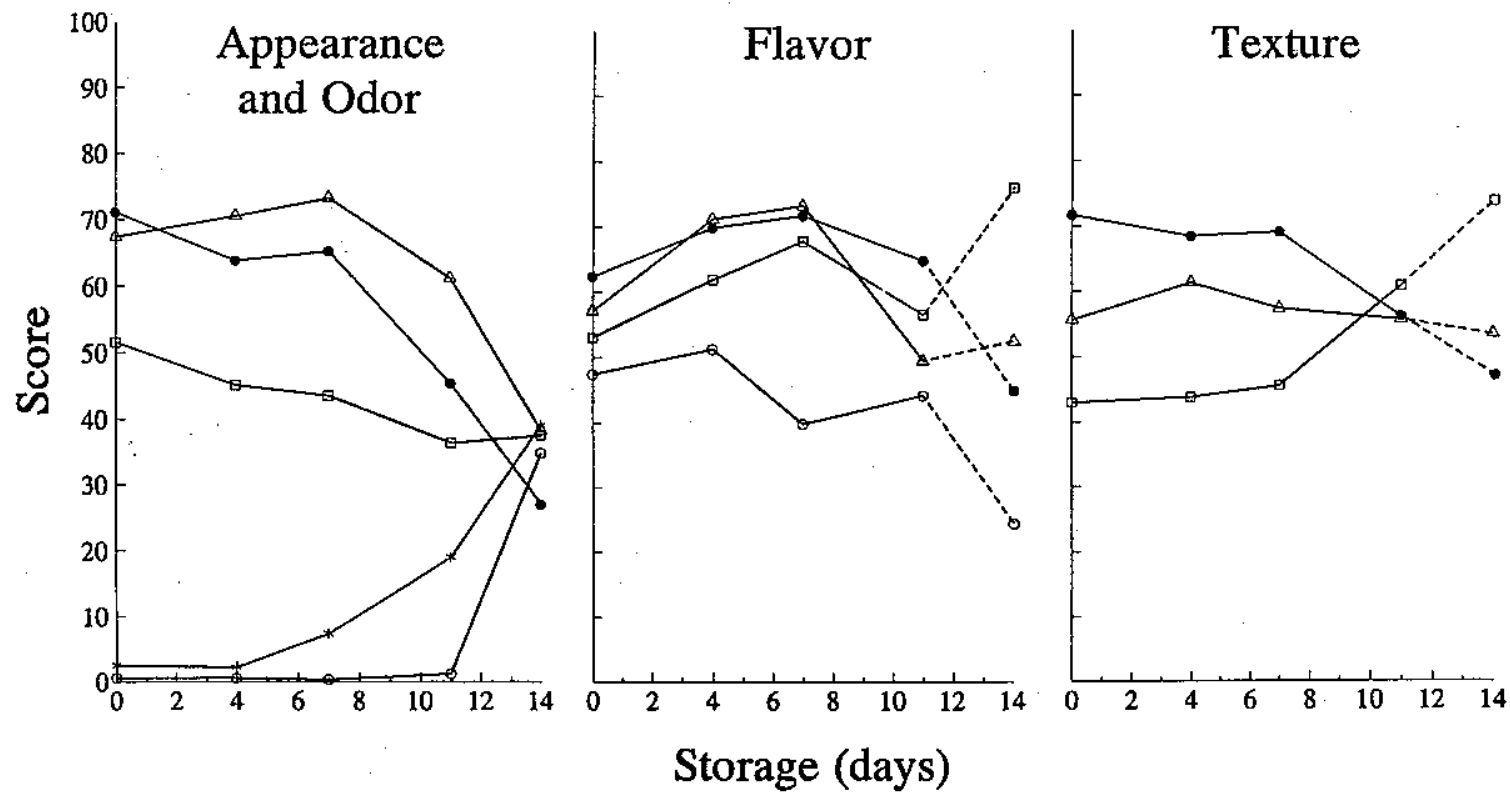

Fig. 3-Sensory changes in pineapple pieces during $4^{\circ} \mathrm{C}$ storage. Appearance: $\bullet$ quality (4.85), $\square$ yellowness $(5.66)$, browning (4.59) Odor: $\Delta$ typical (5.41), 0 other (4.27); Flavor: $\bullet$ quality (4.43), $\Delta$ typical (6.45), $\square$ sweetness (8.42), 0 acidity (7.25); Texture: • quality (4.58), a softness $(5.0 \%), \Delta$ moisture content (4.35). Standard errors of means in brackets. Intensity scales for each attribute, Table 1. Quality scales rated from 0 extremely poor to 100 extremely good. Dashed lines indicate that at 14 days, fruit from one of three replicates was assessed for flavor and texture, as unacceptable appearance of the other sets precluded further tasting.
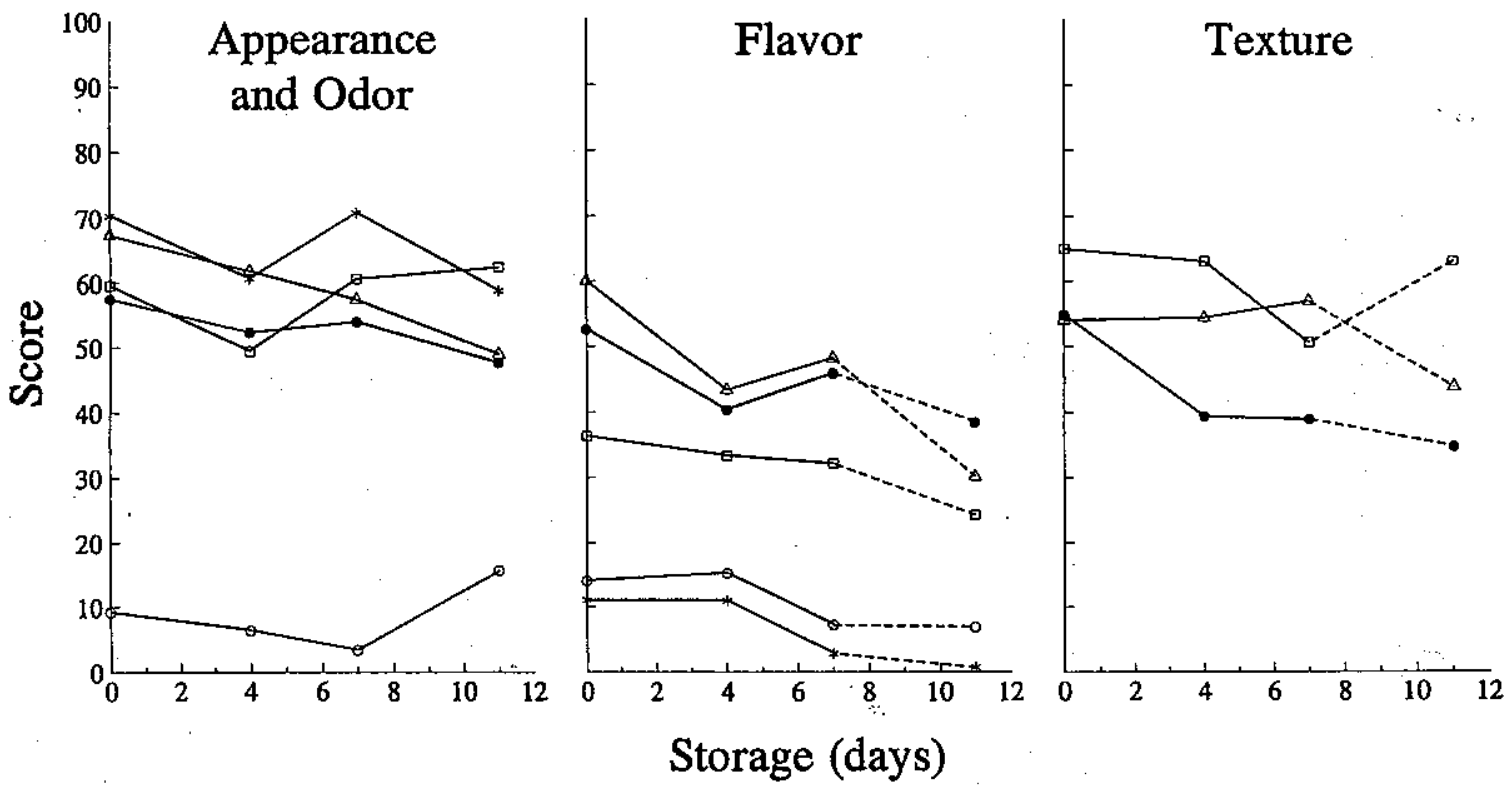

Fig. 4-Sensory changes in cantaloupe pieces during $4^{\circ} \mathrm{C}$ storage. Appearance: $\bullet$ quality $\{4.10)$, a physical appearance $(4.99), *$ color (2.87); Odor: $\Delta$ typical (6.02), o other (4.33); Flavor: $\bullet$ quality (5.52), $\Delta$ typical (5.25), $\square$ sweetness (4.86), o sourness (4.82), * bitterness (2.94); Texture: — quality (6.02), a softness (3.17), $\Delta$ moisture content (3.52). Standard errors of means in brackets. Intensity scales for each attribute, Table 1. Quality scales rated from 0 extremely poor to 100 extremely good. Dashed lines indicate that at 11 days, fruit from two of the three replicates were assessed for flavor and texture, as unacceptable appearance of the third set precluded further tasting.

changes in color were inconsistent. By 11 days white colonies (not identified) were observed on replicate two fruit. Development of a white, translucent appearance and sickly odor was detected in replicate three fruit. Results were far more variable than those for other fruits. This was probably an indication of variability both within and between individual fruits within replicates.

\section{Microbiological counts}

Fresh fruit. Total counts of fresh fruit pieces (Table 2) ranged between $8.8 \times 10^{1} \mathrm{CFU} / \mathrm{g}$ and $1.4 \times 10^{7} \mathrm{CFU} / \mathrm{g}$. Lowest counts occurred in honeydew and highest counts in papaya.
Usually a 10-fold difference between minimum and maximum counts for a particular species occurred. Exceptions were papaya and pineapple where fruit from one trial had total counts $1000-$ fold and 100-fold greater, respectively, than that from other trials. No particular group of microorganisms tested (i.e., lactobacilli, Enterobacteriaceae, yeasts and molds) dominated the microflora of fresh minimally processed fruit (i.e., irrespective of species) or of a particular fruit species.

$4^{\circ} \mathrm{C}$-stored fruit. Total counts of fresh and spoiled kiwifruit, papaya and pineapple were similar (Table 2). The high count of replicate one papayas at the end of shelf life, 1000-fold greater than replicate two and three fruit, did not result in lowered shelf 


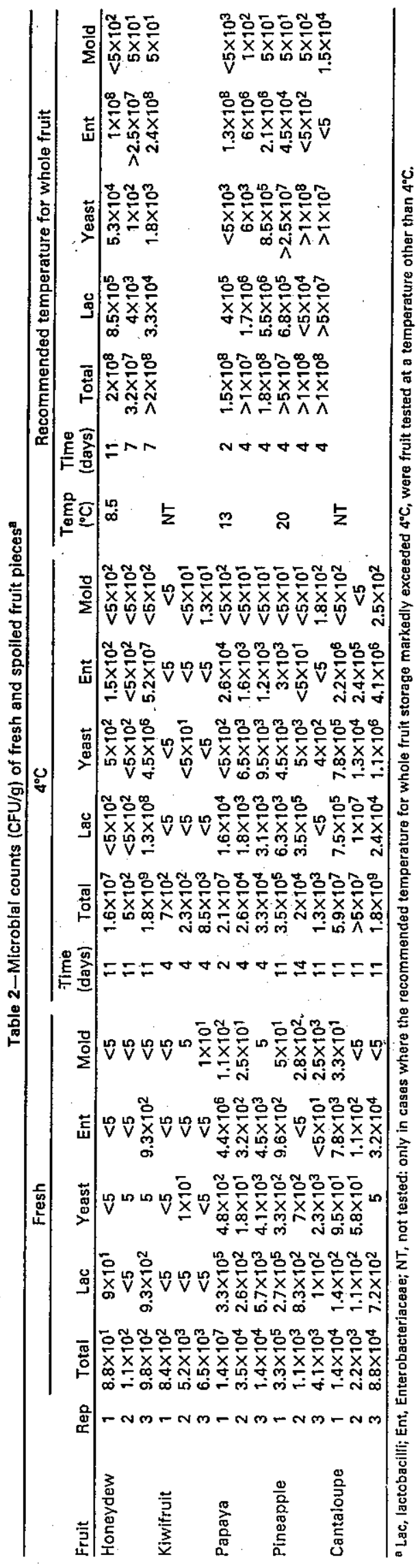

life relative to the others. In contrast to kiwifruit, papaya and pineapple, total counts for cantaloupe and honeydew from trials 1 and 3 had increased markedly after 11 day of storage. Final levels exceeded $10^{7} \mathrm{CFU} / \mathrm{g}$. The 11 days total count of replicate two honeydews, 6 points higher (or more) for appearance, flavor and texture than other melons at 11 days, was only $5 \times 10^{2}$ CFU/g. No particular group of microorganisms dominated the microflora of $4^{\circ} \mathrm{C}$-stored fruit at the end of shelf life.

Fruit stored at higher temperatures. Microorganisms grew more rapidly in fruit stored at $>4^{\circ} \mathrm{C}$ (Table 2). This was most noticeable in replicate two honeydew, total count $5 \times 10^{2} \mathrm{CFU} /$ $\mathrm{g}$ after 11 days at $4^{\circ} \mathrm{C}$, but $3.2 \times 10^{7} \mathrm{CFU} / \mathrm{g}$ after 7 days at $8.5^{\circ} \mathrm{C}$. At the end of shelf life, total counts exceeded $10^{7} \mathrm{CFU} /$ $\mathrm{g}$ in honeydew, papaya and pineapple. Visible colonies occurred in replicate one and three papayas. Enterobacteriaceae counts exceeded $10^{6} \mathrm{CFU} / \mathrm{g}$ in honeydew and papaya, and frequently comprised $>50 \%$ of the total count at the end of shelf life. Yeast counts in stored pineapple were $>2.5 \times 10^{7} \mathrm{CFU} / \mathrm{g}$.

\section{DISCUSSION}

THE SHELF LIFE OF FRUTT PIECES related to the species at $4^{\circ} \mathrm{C}$. kiwifruit and papaya, 2 days; cantaloupe, 4 days; pineapple, 11 days; and honeydew, 14 days. The symptoms of spoilage also differed between species. For example, development of brown discoloration was observed only in pineapples, while bitter flavors developed only in kiwifruit. Microbial growth did not appear to contribute to spoilage in diced kiwifruit, papaya and pineapple, but may have affected honeydew melon and cantaloupe. Kiwifruit, papaya and pineapple pieces became softer during storage.

Most undesirable texture changes in fruit are caused by enzymes such as $\beta$-galactosidase and exo-polygalacturonase which solubilize pectin in cell walls. The main compound which has been used to inhibit softening is calcium chloride. It firms fruit tissue by reacting with pectinic acid to form calcium pectate (King and Bolin, 1989). Our results have shown that lactobacilli, Enterobacteriaceae, yeasts and molds comprised a variable, and often small, proportion of total count on fresh and spoiled fruit pieces after storage at $4^{\circ} \mathrm{C}$. The microflora of minimally processed fruit need further study to determine whether they originate from within fruit tissue as a result of preharvest infection, from skin as a result of environmental contamination, or from processing equipment.

No advantage resulted from storing fruit pieces at temperatures recommended for fruit in its whole form, when they were markedly higher than $4^{\circ} \mathrm{C}$. Both physiological deterioration and microbial growth in honeydew melon, papaya and pineapple pieces were enhanced at higher temperatures. Microbial colonies were observed on each of these fruit at the end of shelf life. Spoilage manifested itself similarly in fruit stored at $4^{\circ} \mathrm{C}$ and higher temperatures. Honeydew melon, papaya and pineapple pieces did not suffer chilling injury when stored at $4^{\circ} \mathrm{C}$. Chilled $\left(0-5^{\circ} \mathrm{C}\right)$ storage appeared to be effective for extending shelf life of such minimally processed fruit. Shewfelt (1986) stated that specifications for monitoring "high" or "salable" quality were difficult to set and vary by commodity and ultimate product application. The profiling scoresheets we developed were successfully used to trace changes in sensory quality during storage.

\section{CONCLUSIONS}

OUR RESULTS established for the first time crude limits for the shelf life of minimally processed honeydew melon, kiwifruit, papaya, pineapple, and cantaloupe. Different fruit pieces spoiled in different ways and consequently there is need to determine factors which limit shelf life of each type fruit. Microfiora of fruit pieces need to be studied to set appropriate criteria for quality assessment. Minimally processed fruit should be chill stored $\left(0-5^{\circ} \mathrm{C}\right)$ and not stored at temperatures recommended for whole fruit, when that is substantially higher than $4^{\circ} \mathrm{C}$.

-Continued on page 1215 
Table 4-Hunter color values of dried pomace from three apple cultivars $\mathrm{a}, \mathrm{b}$

\begin{tabular}{lccc}
\hline Cultivar & $L$ & $a$ & $b$ \\
\hline Golden Delicious & $54.3 \pm 0.6^{\mathrm{c}}$ & $4.8 \pm 0.0^{\mathrm{e}}$ & $18.8 \pm 0.2^{\mathrm{c}}$ \\
Red Delicious & $51.7 \pm 0.1^{\mathrm{d}}$ & $5.5 \pm 0.1^{\mathrm{d}}$ & $18.2 \pm 0.0^{\mathrm{cd}}$ \\
Winesap & $49.4 \pm 0.2^{\mathrm{a}}$ & $6.0 \pm 0.0^{\mathrm{c}}$ & $17.6 \pm 0.1^{\mathrm{d}}$ \\
\hline
\end{tabular}

of $\mathrm{a}$ lightness $(100=$ pure white, $0=$ black $) ; a=$ redness, $b=$ yellowness.

$\mathrm{b} \mathrm{N}=2$.

0.e Means within a column followed by different superscripts are different at $p<0.05$.

scores were found for flavor $(p<0.05)$ and all other attributes $(\mathrm{p}<0.01)$. The cookies were liked moderately.

\section{CONCLUSION}

POMACE is a valuable food source that remains after juice has been squeezed from apples. Pomace from three apple cultivars, with $20.1-26.4 \%$ rice hull as filtering aid, consisted of about 91\% (DWB) dietary fiber and carbohydrates. A light tan, freeflowing dry material prepared and evaluated at two levels in apple pie filling and three levels in oatmeal cookies did not affect color and sensory panel scores. Both products were liked moderately. Many other uses are possible for such pomace in food products.

\section{REFERENCES}

AACC. 1983, Approved Methods of the AACC, 8th ed. American Association of Cereal Chemists, St. Paul, MN.

Anonymous. 1982. Great Baking Begins with White Lily Flour: A Collection of Treasured Southern Baking Recipes. Meredith Publ. Services, Des Moines, IA

Anonymous, 1983. The Apple Barn Cook Book. Wimmer Brothers, Memphis, TN.
AOAC. 1990. Official Methods of Analysis, 15 ed. Association of Official Analytical Chemists, Washington, DC.

Chen, H., Rubenthaler, G.L., Leung, H.K, and Baranowski, J.D. 1988. Chemical, physical, and baking properties of apple fiber compared with wheat and oat bran. Cereal Chem. 65: 244-247.

Hang, Y. 1987. Production of fuels and chemicals from apple pomace. Food Tang, Y. 1987. Production of

Hang, Y.D. and Woodams, E.E. 1984. Apple pomace: a potential substrate for citric acid production by Aspergillus niger. Biotechnol. Lett. 6: 763Hoseney, R.C. 1986. Rice, oat, and barley processing. Ch. 8 in Principles of
Cereal Science and Technology, p. 167-183. American Association of Cereal

Jain, R.K., Ghankrokta, S.S., and Agrawal, J.D. 1984. Isolation and characterisation of pectin from apple pomace. Indian Food Packer 38(6): 65 70.

Jewell, W.J. and Cummings, R.J. 1984. Apple pomace energy and solids recovery. J. Food Sci. 49:407-410.

Little, T.M. and Hills, F.J. 1978. Agricultural Experimentation: Design and Analysis. John Wiley and Sons, New York.

Morris, C.E. 1985. Apple \& pear fiber. Food Eng. 57(1): 72.

Nolan, A.L. 1983. Unusual ingredients create "healthy" pasta. Food Eng.

Oltjen, R.R., Rumsey, T.S., Fontenot, J.P., Bovard, K.P., and Priode, B.M. 1977. Supplementation of apple pomace with nonprotein nitrogen for gestating beef cows. III. Metabolic parameters. J. Anim. Sci. 45: 532-542.

Prosky, L., Asp, N.-G., Schweizer, T.F., DeVries, J.W., and Furda, I. 1988. Determination of insoluble, soluble and total dietary fiber in foods and food products: Interlaboratory study. J. Assoc. Off. Anal. Chem. 71: 1017-1023. Rockland, L.B. and Beuchat, L.R. (Ed.). 1987. Water Activity Theory and Applications to Food. Marcel Dekker Inc., New York.

SAS Institute Inc. 1985. SAS' User's Guide: Basics, Version 5 Edition. SAS Institute Inc., Cary, NC.

Walter, R.H., Rao, M.A., Sherman, R.M., and Cooley, H.J. 1985. Edible fibers from apple pomace. J. Food Sci. 50: 747-749.

Wang, H.J. and Thomas, R.L. 1989. Direct use of apple pomace in bakery products. J. Food Sci. 54: 618-620, 639.

Ms received $1 / 27 / 94 ;$ revised $8 / 8 / 94$; accepted 8/18/94.

Thanks to Dr. R. Toledo, Untv. of Georgia, Athens, for use of the drum dryer and to the Apple Bam and Cider Mill, Sevierville, TN for pomace

The project was supported by research project TN 894 of the Agricultural Experiment Station, The University of Tennessee, Knoxville.

\section{REFERENCES}

Bolin, H.R, and Huxsoll, C.C. 1989. Storage stability of minimally processed fruit. J. Food Process. Preserv. 13: 281-289. Brackett, R.E. 1987. Microbiological consequences of minimally processed
fruits and vegetables. J. Food Qual. 10: 195-206.

Charley, H. 1982. Food Science, 2nd ed. John Wiley \& Sons, Brisbane, QLD.

Charley, H. 1982. Food Science, 2nd ed. John Wiley \& Sons, Brisbane, QLD. Dougherty, R.H. 1990. Future prospects

products. Food Technol. 44: 124, 126.
Huxsoll, C.C. and Bolin, H.R. 1989. Processing and distribution alternatives for minimally processed fruits and vegetables. Food Technol. 43: 124-128. for minimally processed fruits and vegetables. Food Technol. 43: 124-128.
International Commisgion on Microbiological Specification for Foods. 1978. International Commisgion on Microbiological Specification for Foods. 1978. Microorganisms in Foods. 1. Their Significance and

ation, 2nd ed. University of Toronto Press, London.

Kader, A.A. 1985. A summary of CA requirements of recommendations for
fruits other than pome fruits. Proceedings of the Fourth National Confruits other than pome fruits. Proceedings of the Fourth National ConDept. Hortic. Sci., North Carolina State University, Raleigh.

King, A.D. and Bolin, H.R. 1989. Physiological and microbiological storage stability of minimally processed fruits and vegetables. Food Technol. 43. $132-135,139$

Labuza, T.P. and Breene, W.M. 1989. Applications of "active packaging" for improvement of shelf life and nutritional quality of fresh and extended shelf life foods. J. Food Process. Preserv. 13: 1-69.

O'Connor-Shaw, R.E Guthrie, J.A., Dunlop, K.J and Roberts, R 1994. Co liforms in processed mango: Significance and control. Int. J. Food Microbiol. In press.

Powrie, W.D. and Skura, B.J. 1991. Modified atmosphere packaging of fruits and vegetables. Ch. 7, In Modified Atmosphere Packaging of Foods, B. Ooraikul and M. $\mathrm{M}$. Stiles (Ed.), p. 169-245. Ellis Horwood, Sydney, NSW.
Rolle, R.S. and Chism, G.W. 1987. Physiological consequences of minimally processed fruits and vegetables. J. Food Qual. 10: 157-177.

Ronk, R.J., Carson, K.L., and Thompson, P. 1989. Processing, packaging and regulation of minimally processed fruits and vegetables. Food Technol. 43: 136-139.

Shewfelt, R.L. 1986. Postharvest treatment for extending the shelf life of fruits and vegetables. Food Technol. 40: 70-72, 74, 76-78, 80, 89 .

Shewfelt, R.L. 1987. Quality of minimally processed fruits and vegetables J. Food Qual. 10: 143-156.

Standards Australia. 1983. Australian Standard AS 2542.2.2. Australian Standard for Sensory Analysis of Foods, Part 2 - Triangle Test, Sydney, NSW.

Stone, H., Sidel, J., Oliver, S., Woolsey, S., and Singleton, R.C. 1974. Sensory

evaluation by qualitative descriptive analysis. Food Technol. 28: 24-32.

Food and Nutrition Board and National Research Council. 1985. An Eval

uation of the Role of Microbiological Criteria for Foods and Food Ingreuation of the Role of Microbiological Criteria for

Watada, A.E., Abe, K., and Yamuchi, N. 1990. Physiological activities of Watada, A.E., Abe, K., and Yamuchi, N. 1990. Physiological activities
partially processed fruits and vegetables. Food Technol. 44: 116-122.

partially processed fruits and vegetables. Food Technol. 44: 116-122. Department of Primary Industries. Information Series Q188027. QueensDepartment of Primary Industries. Information Series Q. Ms received 4/4/94; revised $7 / 15 / 94 ;$ accepted $7 / 23 / 94$.

The technical assistance of Ifian Tan, the dedication, patience and skill of panelists, and financial assistance provided by the Rural Industries Research and Development Corporation, are gratefully acknowledged. 